\title{
Procedimiento para la obtención cuantitativa del residuo al tratamiento salicílico-metanólico
}

M.a PILAR De luXaN, Dra. en Ciencias Químicas

IET cC

\section{R E S U M E N}

Se presenta un método cuantitativo para realizar el ataque de una sustancia, con agitación magnética, y posterior filtrado del residuo sin ninguna pérdida de producto.

Concretamente se expone su aplicación para el tratamiento con ácido salicílico en medio metanólico de una muestra de cemento portland.

\section{N T R O D U C C I O N}

Existen en la bibliografía varios métodos de tipo químico, mediante los cuales se pueden eliminar, principalmente, los silicatos del clínker, lo que permite el análisis del resto de sus componentes.

Entre ellos se encuentra el desarrollado por Nagerova y Lebedeva (1), que proponen dos reactivos que atacan selectivamente los silicatos cálcicos del clínker: una solución acuosa al $5 \%$ de ácido bórico y una solución de ácido acético glacial en alcohol metílico absoluto. Este método se modificó posteriormente por Fateeva y Kozlova (2), para la determinación del aluminato tricálcico, por su disolución en una solución caliente de sacarosa al $10 \%$, en el residuo procedente del ataque del cemento con ácido bórico.

Fratini (3) hace uso de una solución amoniacal de citrato amónico.

Takashima y Amano emplean el ácido salicílico en solución metanólica, para atacar el clínker y determinar su contenido en aluminato tricálcico; para ello realizan un estudio por difracción de rayos $\mathrm{X}$ del residuo obtenido, observando que se disuelven la cal libre y los silicatos cálcicos, y permanecen el aluminato tricálcico $\left(\mathrm{C}_{3} \mathrm{~A}: 3 \mathrm{CaO} \cdot \mathrm{Al}_{2} \mathrm{O}_{3}\right)$, la fase ferrítica y el yeso (4). El tratamiento original es el siguiente:

"Se introducen $0,5 \mathrm{~g}$ de cemento portland en un vaso de precipitados, $3 \mathrm{~g}$ de ácido salicíclico y $20 \mathrm{ml}$ de metanol, se agita vigorosamente 30 minutos y se filtra. El residuo se lava con metanol y se seca".

Triviño (5), hace aplicación de este último método, empleando asimismo la difracción de rayos $\mathrm{X}$ para el análisis del residuo al tratamiento salicílico-metanólico; y señala que, el lavado del extracto salicílico con agua hirviente durante 10 segundos, descompone la 
fase ferrítica y el aluminato tricálcico, formándose aluminato tricálcico hidratado. Con objeto de eliminar la mayor parte de los sulfatos, trata dicho residuo con una solución de ácido acético $1 \mathrm{~N}$, durante 15 minutos con agitación magnética.

Posteriormente y mediante la espectroscopía de absorción infrarroja, capaz de detectar no sólo componentes cristalinos, sino también fases en estado amorfo, se observa, en la mayoría de los casos, la presencia de silicatos, tricálcico y sobre todo bicálcico aún sin disolver, en el residuo del ataque salicílico-metanólico de un cemento portland (6) (7). También se detectan en el insoluble la sílice tanto cristalizada como vítrea, y por consiguiente, las adiciones silíceas (puzolanas naturales, cenizas volantes, ...) que pueda tener incorporadas el cemento, ya que quedan prácticamente inalteradas al realizar sobre ellas este tratamiento (7).

El valor del residuo al ataque salicílico-metanólico de una muestra de cemento anhidro es indicativo de la existencia de adición silícea y del porcentaje en que se encuentra presente en el cemento, debido a la insolubilidad de las adiciones silíceas ante este tratamiento (7).

Con el fin de obtener dicho residuo, se ha diseñado un aparato de agitación-filtración sin pérdida de producto y se ha desarrollado un método operativo para realizar con precisión este tratamiento, cuya descripción es el objeto del presente trabajo.

\section{TRATAMIENTO CON ACIDO SALICILICO EN SOLUCION METANOLICA SIN PERDIDA DE PRODUCTO}

\section{Aparato}

Para llevar a cabo un correcto ataque de la muestra, y con el fin de evitar cualquier pérdida de producto, se ha diseñado el modelo de aparato representado en las figuras 1-I y 1-II, (8).

Consta, básicamente, de un matraz de dos bocas donde se realiza la agitación y el posterior lavado como se indica en el método, y una placa filtrante (G-4), que se adosa a dicho matraz para el filtrado del residuo sin ninguna pérdida.

\section{Reactivos}

- Acido salicílico (o-hidroxibenzoico) puro para análisis.

- Metanol de 99,9 \% de riqueza, seco y destilado sobre $\mathrm{CaO}$.

- 0,5000 gramos de muestra seca a $105^{\circ} \mathrm{C}$ hasta peso constante.

\section{Método}

Se colocan $0,5000 \mathrm{~g}$ de muestra seca y $3,0000 \mathrm{~g}$ de ácido salicílico en el matraz, previamente tarado, en la posición de agitación, acoplándose la placa filtrante, igualmente tarada, como se indica en las figuras 1-I y 2-I. Se añaden $20 \mathrm{ml}$ de metanol. Se tapa la segunda boca del matraz. Se mantiene con agitación vigorosa 30 minutos. 


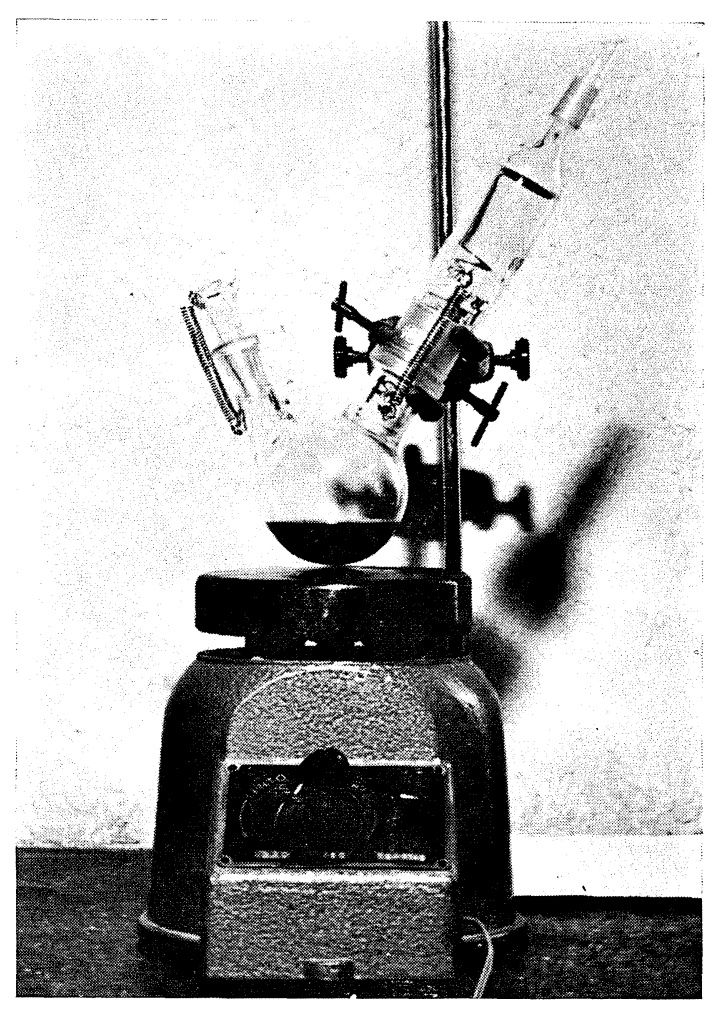

Fig. 1-I

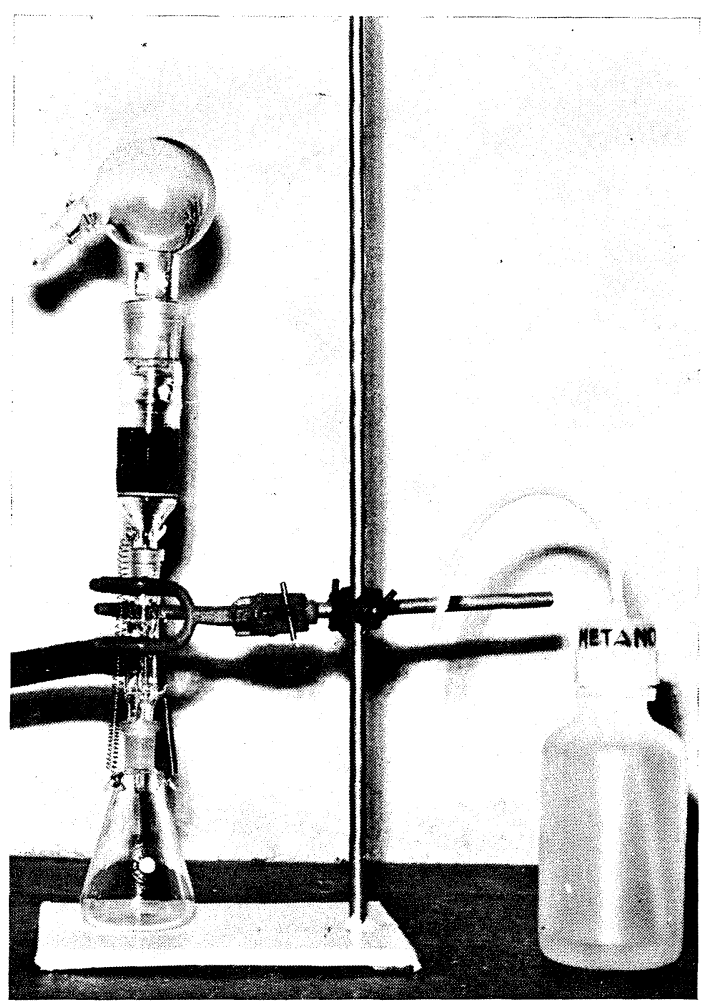

Fig. 1-II

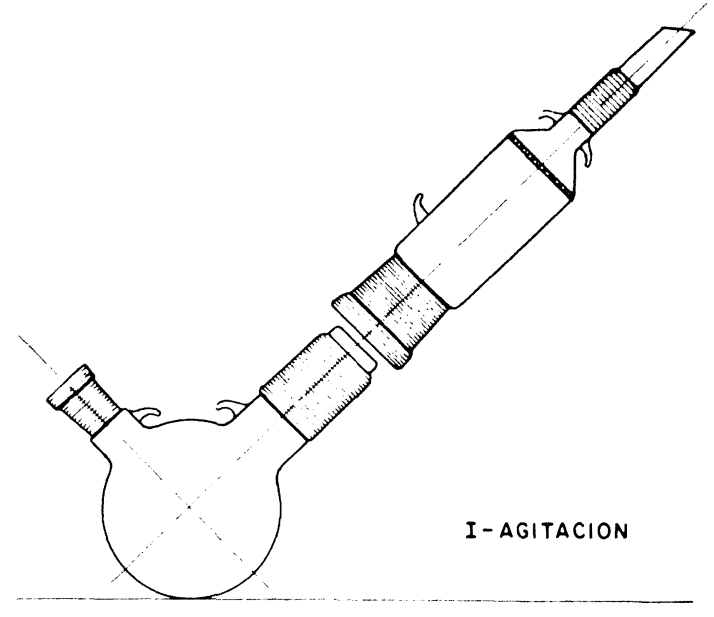

Fig. 2-1

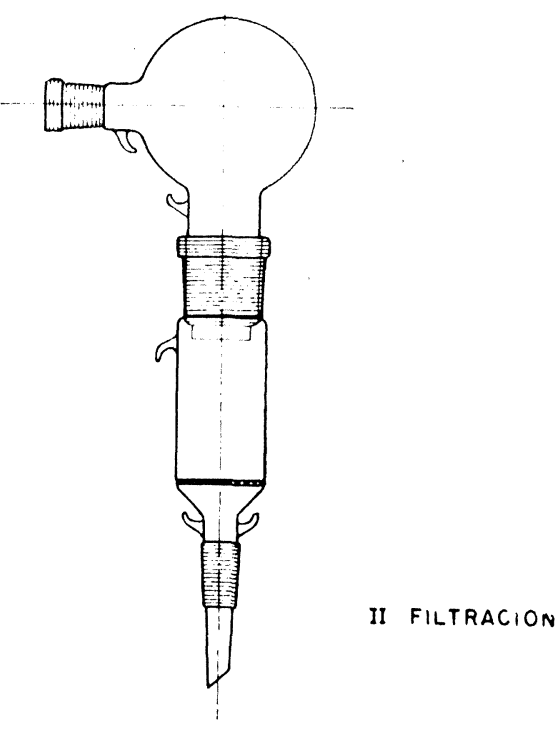

Fig. 2-II

Se filtra a vacío (figs. 2-I y 2-II) y se lava el residuo con $50 \mathrm{ml}$ de metanol, extrayendo el agitador. Se introducen placa y matraz en estufa a $105^{\circ} \mathrm{C}$, hasta peso constante. La diferencia de pesos conducirá al valor del residuo. 


\section{O N C L U S I O N E S}

1. Es posible obtener el valor del residuo al ataque con ácido salicílico en medio metanólico sin pérdida de producto de una sustancia, mediante el aparato expuesto en este trabajo.

2. El aparato diseñado podrá ser de aplicación para cualquier tipo de ensayo semejante al tratamiento salicílico-metanólico, es decir, ataque de la muestra con agitación magnética, y posterior filtrado sin pérdida de producto.

\section{B I B L I O G R A F I A}

(1) Nagerova, E. I., Lebedeva, A. D.: Cement, núms. 2-3, 23-26, (1941).

(2) Fateeva, N. I., Kozlova, V. K.: Cement, núm. 4, 13-14, (1966).

(3) Fratini, N.: Rc. Sc., 26-2747, (1956).

(4) Takashima, S., Amano, F.: Review 30 th Gl. Meet. Tokio., Semento Gijutsu Nenpo, XIII, 7-9, (1959).

(5) Triviño, F.: Materiales de Construcción, núm. 143, 21-24, (1971).

(6) Vazquez, T.: Tesis Doctoral, Fac. Ciencias, Universidad Complutense (1975).

(7) De Luxan, M. P.: Tesis Doctoral, Fac. Ciencias, Universidad Complutense (1975).

(8) De Luxan, M. P.: Patente Española núm. 435.971 (24/3/1975). 